\title{
COLLAGEN CROSS-LINKER EFFECT ON THE MECHANICAL PROPERTIES OF THE RADICULAR HYBRID LAYER IN RESTORATIVE DENTISTRY: A NANOINDENTATION STUDY
}

\author{
GIANPAOLO SERINO ${ }^{1}$, CRISTINA BIGNARDI ${ }^{1}$, CLELIA BOCCAFOSCHI $^{1}$, \\ NICOLA SCOTTI ${ }^{2}$, ELIO BERUTTI ${ }^{2} \&$ ALBERTO AUDENINO $^{1}$ \\ ${ }^{1}$ Department of Mechanical and Aerospace Engineering, Politecnico di Torino, Italy \\ ${ }^{2}$ Department of Surgical Sciences, University of Turin, Italy
}

\begin{abstract}
Bond strength between the dentin and the restorative resins is deeply dependent on the nature of their interface. Resins impregnate dentin, which is rich in collagen fibers. This in vitro study aimed to evaluate the effect of collagen carbodiimide cross linker agent (EDC) on the mechanical properties of the adhesive interface in endodontically treated teeth. Twenty upper premolar teeth were selected and divided into two groups according to the dentin pretreatment procedures: no EDC application (group A) and EDC application (group B). Three typical zones, i.e. the dentin, the radicular hybrid layer and the resin, were analyzed using a Nanoindenter XP equipped with a diamond Berkovich indenter. The input curve was characterized by loading and unloading phases with a strain rate value of $0.1 \mathrm{~s}^{-1}$ and, an intermediate dumbbell phase of $30 \mathrm{~s}$. The maximum indentation depth was set to be $200 \mathrm{~nm}$. The load-displacement curves were analyzed by using the "Oliver and Pharr" method. The mean values of nanoindentation modulus were determined for the dentin, the radicular hybrid layer and the resin for both the samples with and without crosslinker. In general, the application of EDC was found to modify the mechanical properties of the radicular hybrid layer. The mechanical properties of the radicular hybrid layer could be related to the efficient infiltration of the adhesive systems and collagen crosslinker through dentin.

Keywords: quasi-static nanoindentation, hybrid layer, collagen crosslinker, mechanical properties.
\end{abstract}

\section{INTRODUCTION}

The discipline of dental science includes the diagnosis of diseases in the mouth and teeth, and the procedures involved in restoration of their integrity and function. Restoration of lost tooth structure with suitable materials play an integral part in the successful rehabilitation of oral tissue.

There are many examples of clinical problems that went through from a qualitative assessment to a quantitative evaluation thanks to their modelling [1], [2], furthermore, the application of classical experimental methods of structural analysis to the evaluation of the efficacy of procedures or surgical techniques [3]-[7] or to the evaluation of the mechanical characteristics of the materials used at different scales of investigation [8]-[10] pushed the dental science forward.

The study of Buonocore [11] was the first to report that etching the enamel, to expose the underling organic matrix of the tooth, improved the bond strength between the resin and the enamel. The ability of the resin to penetrate the organic collagen network and envelope apatite crystallites played a crucial role [12]. A transition zone defined hybrid layer, by Nakabayashi et al. [13], and better observed through scanning electron microscopy [14] confirms what was already found by Gwinnett and Matsui [12]. Exposed collagen matrix acts like a scaffold [15] where the resin can infiltrate and establish a strong and durable bonding with enamel or dentin. 
As reported in literature [16], the adhesion process to dentin or enamel occurs in two different phases. In a first step the inorganic component is etched generating the structure that in a successive step, defined hybridization phase, will be perfused by the resin. Depending on the adhesion strategy, which Van Meerbeek classified in "etch and rinse" or "self-etch" [16] the adhesion process can be performed in one, two or three phases correlated to the number of steps required for the application of the resin. The adhesion strategy adopted in this study was the "etch and rinse", in this case the bonding lies mostly on the diffusion of the resin into the collagen scaffold. The weak affinity between the functional groups of the monomers and the exposed collagen make their chemical bonding very unlikely [16].

Although the findings of Buonocore pushed the use of dental resins in a new scenario, some issues still are not completely overcome. Dealing with these adhesion procedures imply a pre-treatment of dentin to eliminate the inorganic phase by using phosphoric acid solution. Acidic treatment of the dentin onset the activation of the metalloproteinases (MMPs) through an acid activation mechanism [17]. This procedure combined with the ionic and hydrophilic nature of dental adhesives currently adopted, leads to the hydrolysis of collagen fibers [18][20]. The MMPs activation and the water adsorption lead to a decline over time of the hybrid layer and to a consequent failure of the bonding between the dentin and the resin [21].

Integrity of the collagen network is essential to preserve the stability and ensure the durability of the hybrid layer over time. The use of crosslinkers is able to establish covalent bonding with the exposed site of the enzymes in order to inactivate the MMPs is one of the strategies currently applied [22]-[24]. The 1-ethyl-3(3-dimethylaminopropyl) carbodiimide (EDC) is able to reduce the hydrolysis of collagen fibers [21] and stabilize the collagen matrix [25], [26]. Moreover, treating the exposed collagen network with EDC for less than 1 minute increases its stiffness [25], [27], and preserves the dentin bond strength when aged over than one year in artificial saliva [28].

Bond strength between dentin and the resin composite is deeply dependent by the nature of their interface [29], [30]. Nanoscopic Dynamic Mechanical Analysis (nanoDMA) was applied to investigate the influence of the EDC [31] and, the effect of the biomimetic remineralization [32] on the hybrid layer, furthermore, combining this technique with fatigue test allowed to analyze the hybrid layer when undergone to cycling stress [33].

Effectiveness of the application of crosslinkers, such as EDC and chlorhexidine, on the durability of dentin-resin bond, was also evaluated through microtensile test [33], [34].

All the studies reported the good efficacy of the EDC crosslinker to preserve the bond strength over time.

Thus far, quasi-static nanoindentation test were performed to evaluate the nanomechanical properties of the enamel and the dentin [35]-[37] or to evaluate the performance of cements in dental restoration [10], and in the 1993 by Van Meerbeek's group to study the effect of 4 different adhesive systems and conditioning agent on the resin-dentin bonding area [29].

Even if the nanoDMA method permits to obtain a useful mapping of the mechanical properties of the hybrid layer with a very fine resolution, in order to obtain information from the single phases that compose it, in this in vitro study quasi-static nanoindentation method was adopted to evaluate the effect of EDC on the mechanical properties of the adhesive. When opportunely set, through quasi-static nanoindentation method is possible to identify the mechanical properties of the hybrid layer as a result of the contribution of all the phases that compose it. 


\section{MATERIALS AND METHODS}

\subsection{Restoration procedure}

Twenty upper premolars teeth, extracted for periodontal reasons, were selected. The inclusion criteria were: sound teeth extracted within one month, with nearly similar root size (length $>12 \mathrm{~mm}$ ) and no cracks under trans-illumination and magnification.

After 24 hours in water storage at $37^{\circ} \mathrm{C}$, a standardized post space, $8 \mathrm{~mm}$ depth, was prepared in each sample with a dedicated bur, etched for $15 \mathrm{~s}$ (Ultraetch, Ultradent Products Inc.) with phosphoric acid, rinsed for $30 \mathrm{~s}$ and dried with air and paper point. Then, samples were divided in 2 groups (10 samples for each group) according to the dentin pretreatment procedure: no EDC application (group A) and EDC application (group B). In all samples, a universal adhesive system (Scotchbond Universal, 3M Science Applied to Life $^{\mathrm{TM}}$ ) was employed in multiple application. A red stain was added to the adhesive system in order to better recognize the hybrid layer. Then, fiber posts (Rebilda Post $\varnothing 1.2 \mathrm{~mm}$, Voco GmbH) were luted with a dual-curing luting cement (Rely-x Universal, 3M Science Applied to Life $^{\mathrm{TM}}$ ) and cured for $180 \mathrm{~s}$ (Celalux LED lamp, Voco GmbH). The coronal cavity was restored with a nanohybrid composite (Filtek Supreme XTE, 3M Science Applied to Life ${ }^{\mathrm{TM}}$ ).

\subsection{Sample preparation}

The samples were embedded in resin and then sectioned with diamond saw in $1 \mathrm{~mm}$ thick slices perpendicularly to the longitudinal axis, from the occlusal surface until the post end. Each slice was flattened with ascending sandpapers till 2400 grit and, opportunely polished in order to reach a reasonable value of the mean surface roughness [38].

From the center of the slice three typical regions can be identified. The cement in the center and, in the outermost circular crown the dentin. The hybrid layer is the transition zone where the adhesive system infiltrates the etched dentin, with and without pretreatment.

\subsection{Nanoindentation procedure}

Tests were carried out with the Nanoindenter XP (MTS System Corporation), equipped with a diamond Berkovich indenter and characterized by a theoretical force resolution of $50 \mathrm{nN}$ and a theoretical displacement resolution lower than $0.01 \mathrm{~nm}$. The shape function of the indenter and the frame stiffness of the instrument were fine calibrated following the standard procedure [39]. Input curve is characterized by loading and unloading phases imposing a strain rate value of $0.1 \mathrm{~s}^{-1}$. Before the onset of the unloading step the maximum load value was held for $30 \mathrm{~s}$.

Depending on the etching agent used during the pretreatment procedure the width of the hybrid layer varies from $3 \mu \mathrm{m}$ to $6 \mu \mathrm{m}$ [30], [32]. Tests were performed in displacement control imposing a maximum value of indentation depth of $200 \mathrm{~nm}$ to assure that only the mechanical properties of the hybrid layer were analyzed. The cross-section value obtained from the calibration procedure at the set indentation depth is compatible with the hybrid layer width [40]. Imposing such limit of the indentation depth allows to analyze only the mechanical properties relative to the region of interest given the compatible dimensions of the area under the indenter and the indented portion of the tooth slice.

The loading-displacement curves were then analyzed by using the Oliver and Pharr method [39] in order to obtain the nanoindentation modulus. 


\subsection{Statistical analysis}

For each slice 20 indentation points have been selected for the resin, the hybrid layer and, the dentin. A total of 800 indentations for group A and for group B for every region respectively were performed. The outliers were identified and discarded through the modified Thompson Tau Test before applying the one-way analysis of variance (ANOVA) test $(p<0.05)$. In this study we recognize two levels: no application of EDC (group A) and application of EDC (group B). Nanoindentation modulus is the independent variable.

\section{RESULTS AND DISCUSSION}

Representative nanoindentation curves obtained for the dual-curing cement, the dentin and, the hybrid layer is shown in Fig. 1.
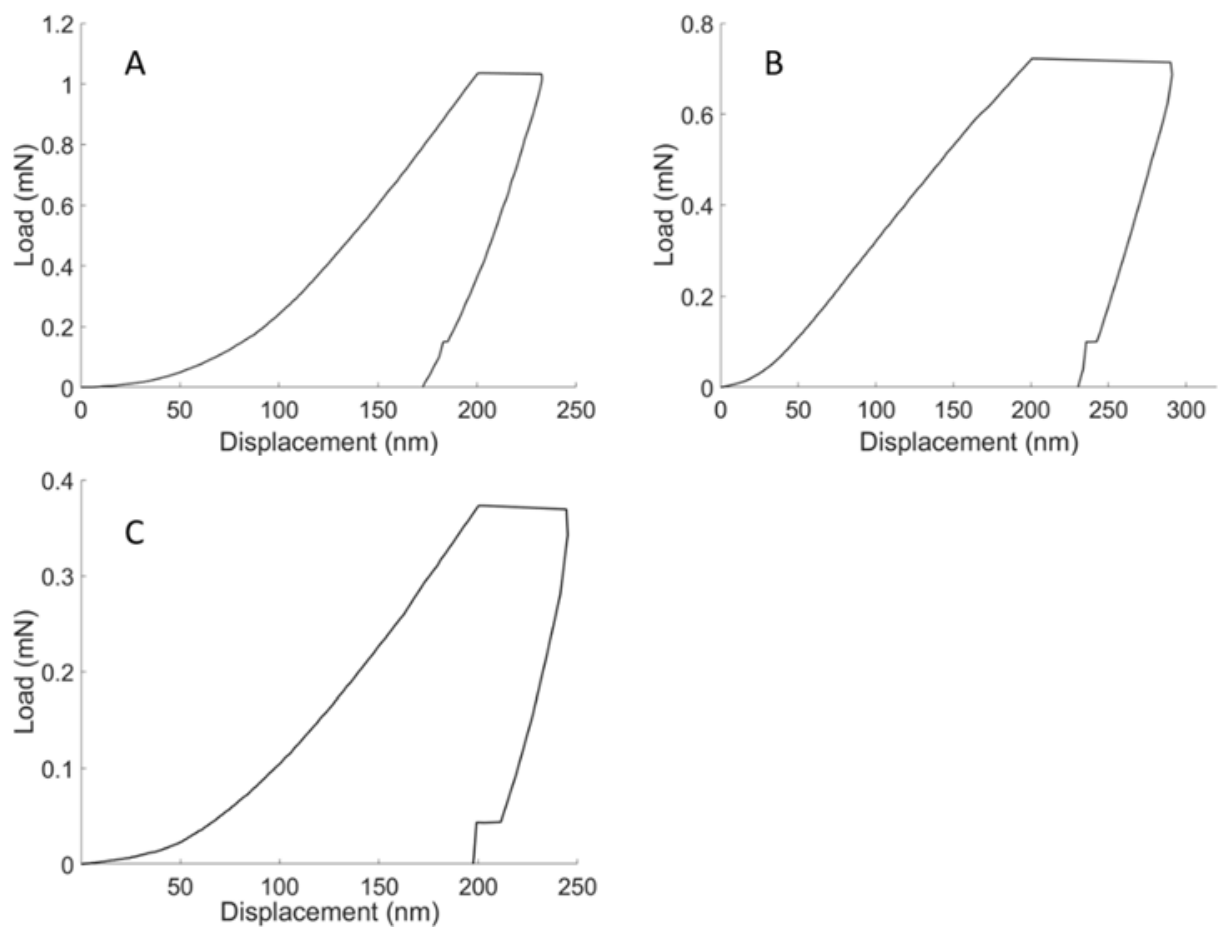

Figure 1: Representative nanoindentation curves obtained for: (a) Dentin; (b) Hybrid layer; (c) Resin.

The amount of residual deformation seems to indicate that plasticization phenomena were occurred. However, observing the indentation site at the end of the test no residual imprints were detected. In other words, the misleading plastic deformation is due to the viscous properties of the materials under investigation. When the load is totally removed the deformation recovery continues, and the imprint becomes undetectable, such phenomenon was already observed elsewhere [41]. No plasticization limit was reached to produce permanent deformation due to the magnitude of the applied load. The holding time defined before the onset of the unloading phase stabilize the time-dependent phenomena [42], [43], allowing to apply the Oliver and Pharr method and calculate the nanoindentation modulus 
and the hardness of the cement. The displacement registered during the dwell time reported in Fig. 1(A) indicates that the collagen fibers, which compose the dentin, heavily contribute to defining the behavior of the tissue. Such response, better known as creep, characterizes the class of polymeric materials. The displacement relative to the hybrid layer registered during the dwell period is the higher when compared with the other two indented materials, indicating a higher creep rate as summation of the effect due to the cement and to the collagen fibers. Quantitative analysis of the nanoindentation curves is reposted in Fig. 2.
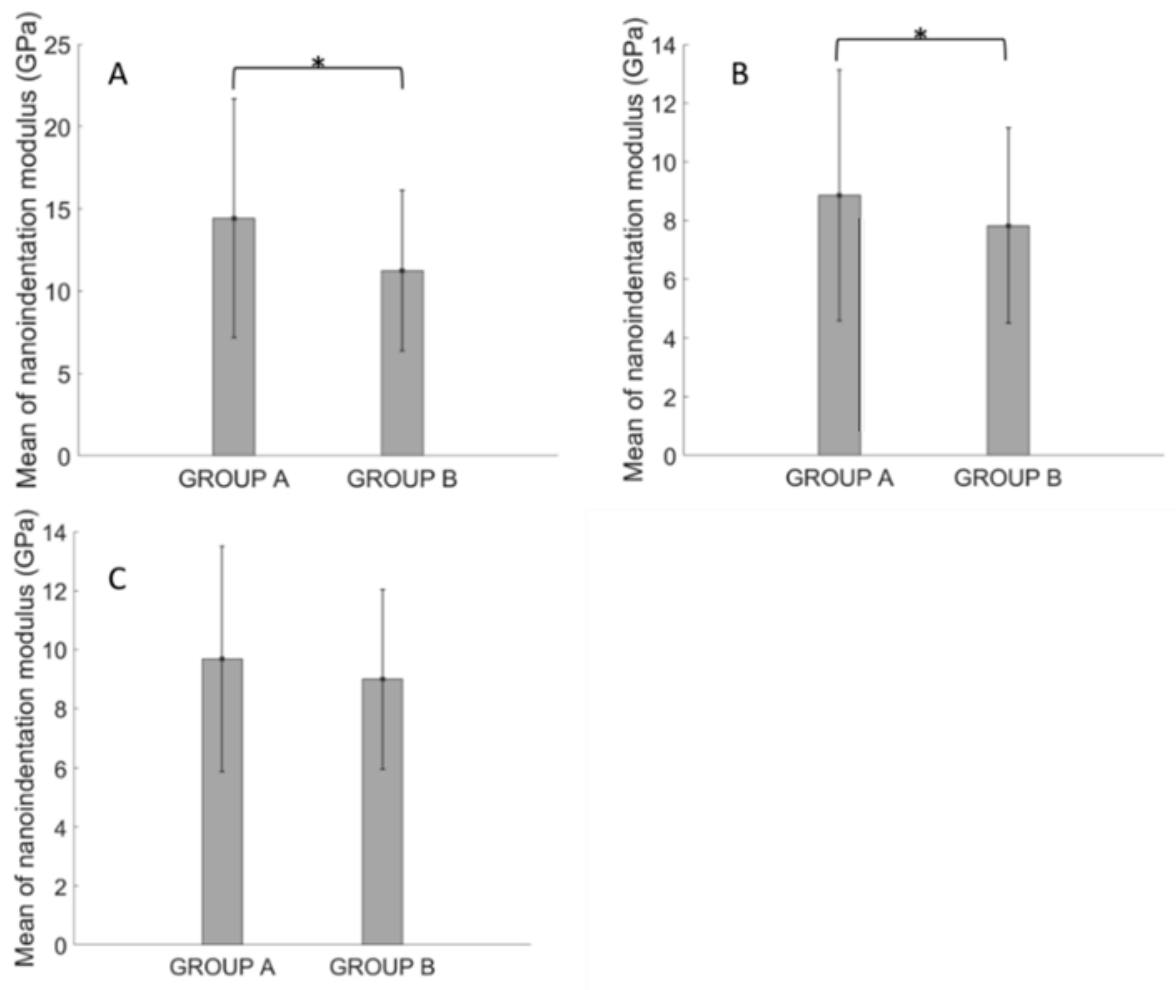

Figure 2: Nanoindentation Modulus obtained for: (a) Dentin; (b) Hybrid layer; (c) Resin. Values of nanoindentation modulus of the dentin and hybrid layer are significant different for group A and group B $(\mathrm{p}<0.05)$.

The higher values of nanoindentation modulus were registered for the dentin due to the presence of the inorganic material. Nanoindentation modulus mean values of dentin were respectively $11.255( \pm 4.871) \mathrm{GPa}$ and $14.430( \pm 7.249) \mathrm{GPa}$ for the samples with EDC and without.

As can be expected, the values obtained for the cement and the hybrid layer are very close to each other since the hybrid layer is generated by the impregnation of demineralized dentin by the cement.

Nanoindentation modulus mean values of cement, obtained for the samples with and without EDC, were respectively $8.998( \pm 3.804) \mathrm{GPa}$ and $9.690( \pm 3.033) \mathrm{GPa}$. Nanoindentation modulus mean values of the radicular hybrid layer were respectively 7.828 $( \pm 3.331) \mathrm{GPa}$ and $8.855( \pm 4.281) \mathrm{GPa}$. 
The mechanical properties of the dentin evaluated for the sample obtained using the EDC are significantly lower than those obtained without EDC $(\mathrm{p}<0.05)$. The statistical difference, however, cannot be ascribed to the EDC application considering that, the indentation sites for the dentin were chosen far away from the region where the EDC was applied. As matter of fact the statistical difference is due to the microstructure features of the dentin composition, in other words the inter-variability between the two samples is due to the collagen fiber network that encloses the inorganic phase and not to the EDC application [44], [45].

No significant differences of the resin mechanical properties were found $(p>0.05)$ between group A and group B, as can be expected. The statistical analysis revealed, furthermore, that the EDC application slightly modify the mechanical properties of the radicular hybrid layer $(p<0.05)$. Counterintuitive reduction of the nanoindentation modulus values of the hybrid layer obtained for the spacemen of group B can be explained observing that the mechanical properties of the dentin sample of this group are, on average, minor than those registered for the control sample (group A). In other words, the slight, even if significant difference between the mechanical properties obtained for the hybrid layer indicates that the EDC crosslinker increases the links between the collagen fiber, [25]-[27], [46], [47] matching the mechanical properties of the hybrid layer of the two groups.

\section{CONCLUSION}

The settings here adopted allow one to homogenize the contribution of the collagen fibers and the cement trying to understand if the application of EDC for a period of $30 \mathrm{~s}$ modifies the mechanical response of the hybrid layer as whole. The slight reduction of the nanoindentation modulus of the hybrid layer observed for the EDC treated sample must be ascribed to the microstructure of the dentin, that is characterized by a lower mean value of nanoindentation modulus compared to that of the specimens of group B. Indeed, it can be speculated that the cross-linker application of $30 \mathrm{~s}$ increases the links between the collagen fibers strengthening the demineralized dentin and the resin-dentin bonding.

\section{REFERENCES}

[1] Vitale, M.C., Chiesa, M., Coltellaro, F., Bignardi, C., Celozzi, M. \& Poggio, C., FEM analysis of different dental root canal-post systems in young permanent teeth. European Journal of Paediatric Dentistry, 9(3), pp. 111-117, 2008.

[2] Calì, M. et al., Influence of thread shape and inclination on the biomechanical behaviour of plateau implant systems. Dental Materials, 34(3), pp. 460-469, 2018.

[3] Menicucci, G., Ceruti, P., Barabino, E., Screti, A., Bignardi, C. \& Preti, G., A preliminary in vivo trial of load transfer in mandibular implant-retained overdentures anchored in 2 different ways: allowing and counteracting free rotation. The International Journal of Prosthodontics, 19(6), pp. 574-576, 2006.

[4] Boero Baroncelli, A., Reif, U., Bignardi, C. \& Peirone, B., Effect of screw insertion torque on push-out and cantilever bending properties of five different angle-stable systems. Veterinary Surgery, 42(3), pp. 308-315, 2013.

[5] Manzella, C., Burello, V., Bignardi, C., Carossa, S. \& Schierano, G., A Method to improve passive fit of frameworks on implant-supported prostheses: An in vivo study. The International Journal of Prosthodontics, 26(6), pp. 577-579, 2014.

[6] Bignardi, C., Zanetti, E.M., Terzini, M., Ciccola, A.R., Schierano, G. \& Audenino, A.L., Reliability, learnability and efficiency of two tools for cement crowns retrieval in dentistry. The Open Biomedical Engineering Journal, 12(1), pp. 27-35, 2018. 
[7] Zanetti, E.M., Pascoletti, G., Calì, M., Bignardi, C. \& Franceschini, G., Clinical assessment of dental implant stability during follow-up: What is actually measured, and perspectives. Biosensors, 8(3), p. 68, 2018.

[8] Bresciano, M., Schierano, G., Manzella, C., Preti, G., Screti, A. \& Bignardi, C., Retention of luting agents on implant abutments of different height and taper. Clinical Oral Implants Research, 16, pp. 594-598, 2005.

[9] Bignardi, C., Petraroli, M. \& Pugno, N., Nanoindentations on conch shells of gastropoda and bivalvia molluscs reveal anisotropic evolution against external attacks. Journal of Nanoscience and Nanotechnology, 10(10), pp. 6453-6460, 2010.

[10] Peluccio, M.S., Bignardi, C., Lombardo, S., Montevecchi, F.M. \& Carossa, S., Comparative study of nanomechanical properties of cements used in teeth restoration. Journal of Physics: Condensed Matter, 19(39), p. 395003, 2007.

[11] Buonocore, M.G., A simple method of increasing the adhesion of acrylic filling materials to enamel surfaces. Journal of Dental Research, 34, pp. 849-853, 1955.

[12] Gwinnett, A.J. \& Matsui, A. A study of enamel adhesives. The physical relationship between enamel and adhesive. Archives of Oral Biology, 12(12), pp. 1615-1620, 1967.

[13] Nakabayashi, N., Kojima, K. \& Matsuhara, E., Promotion of adhesion by infiltration monomers into tooth substrates. Journal of Biomedical Materials Research, 16, pp. 265-73, 1982.

[14] Inokoshi, S., Hosoda, H., Harnirattisai, C. \& Tatsumi, T., A study on the resinimpregnated layer of dentin Part I. A comparative study on the decalcified and undecalcified sections and the application of argon ion beam etching to disclose the resin-impregnated layer of dentin. Japanese Journal of Conservative Dentistry, 33, pp. 427-442, 1990.

[15] Jain, A. \& Bahuguna, R., Role of matrix metalloproteinases in dental caries, pulp and periapical inflammation: An overview. Journal of Oral Biology and Craniofacial Research, 5(3), pp. 212-218, 2015.

[16] Van Meerbeek, B. et al., Buonocore memorial lecture. Adhesion to enamel and dentin: current status future challanges. Operative Dentistry, 23, pp. 215-235, 1998.

[17] Bhoopathi, P.G., Kittappa, K.K., Sanjeev, K. \& Sekar, M., Effect of chlorhexidine and cystatin incorporated adhesives on MMPs and cysteine cathepsin-an in-vitro zymographic analysis. Journal of Clinical and Diagnostic Research, 12(7), pp. ZC01ZC05, 2018.

[18] Hashimoto, M., Ohno, H., Sano, H., Kaga, M. \& Oguchi, H., Degradation patterns of different adhesives and bonding procedures. Journal of Biomedical Materials Research - Part B Applied Biomaterials, 66(1), pp. 324-330, 2003.

[19] Kern, M., Pashley, D., Adelung, R., Ludwig, K., Bosmann, K. \& Yang, B., Effect of structural change of collagen fibrils on the durability of dentin bonding. Biomaterials, 26(24), pp. 5021-5031, 2005.

[20] Hashimoto, M., Oguchi, H., Sano, H., Endo, K., Ohno, H. \& Kaga, M., In vivo degradation of resin-dentin bonds in humans over 1 to 3 years. Journal of Dental Research, 79(6), pp. 1385-1391, 2000.

[21] Mazzoni, A. et al., Carbodiimide inactivation of MMPs and effect on dentin bonding. Journal of Dental Research, 93(3), pp. 263-268, 2014.

[22] Montagner, A.F., Sarkis-Onofre, R., Pereira-Cenci, T. \& Cenci, M.S., MMP inhibitors on dentin stability. Journal of Dental Research, 93(8), pp. 733-743, 2014.

[23] Tjäderhane, L., Dentin bonding: can we make it last? Operative Dentistry, 40(1), pp. 4-18, 2015. 
[24] Tjäderhane, L. et al., Optimizing dentin bond durability: Control of collagen degradation by matrix metalloproteinases and cysteine cathepsins. Dental Materials, 29(1), pp. 116-135, 2013.

[25] Bedran-Russo, A.K.B., Pashley, D.H., Agee, K., Drummond, J.L. \& Miescke, K.J., Changes in stiffness of demineralized dentin following application of collagen crosslinkers. Journal of Biomedical Materials Research Part B: Applied Biomaterials, 86B(2), pp. 330-334, 2007.

[26] Zhang, Z. et al., Effect of carbodiimide on the fatigue crack growth resistance of resindentin bonds. Dental Materials, 32(2), pp. 211-222, 2016.

[27] Castellan, C.S., Pereira, P.N.R., Viana, G., Chen, S.N., Pauli, G.F. \& Bedran-Russo, A.K., Solubility study of phytochemical cross-linking agents on dentin stiffness. Journal of Dentistry, 38(5), pp. 431-436, 2010.

[28] Mazzoni, A. et al., Effect of carbodiimide (EDC) on the bond stability of etch-andrinse adhesive systems. Dental Materials, 29(10), pp. 1040-1047, 2013.

[29] Roos, J.R. et al., Assessment by nano-indentation of the hardness and elasticity of the resin-dentin bonding area. Journal of Dental Research, 72(10), pp. 1434-1442, 1993.

[30] Celis, J.P. et al., Chemical characterization of the resin-dentin interface by microraman spectroscopy. Journal of Dental Research, 72(10), pp. 1423-1428, 1993.

[31] Tezvergil-Mutluay, A., Zhang, Z., Arola, D., Pashley, D.H., Mutluay, M. \& Tay, F.R., Effects of EDC crosslinking on the stiffness of dentin hybrid layers evaluated by nanoDMA over time. Dental Materials, 33(8), pp. 904-914, 2017.

[32] Ryou, H. et al., Effect of biomimetic remineralization on the dynamic nanomechanical properties of dentin hybrid layers. Journal of Dental Research, 90(9), pp. 1122-1128, 2011.

[33] Mutluay, M.M., Yahyazadehfar, M., Ryou, H., Majd, H., Do, D. \& Arola, D., Fatigue of the resin-dentin interface: A new approach for evaluating the durability of dentin bonds. Dental Materials, 29(4), pp. 437-449, 2013.

[34] Ricci, H.A., Sanabe, M.E., De Souza Costa, C.A., Hebling, J. \& Pashley, D.H., Chlorhexidine increases the longevity of in vivo resin-dentin bonds. European Journal of Oral Sciences, 118(4), pp. 411-416, 2010.

[35] Habelitz, S., Marshall, S.J., Marshall, G.W. Jr \& Balooch, M., Mechanical properties of human dental enamel on the nanometre scale. Archives of Oral Biology, 46, pp. 173-183, 2001.

[36] Brauer, D.S., Hilton, J.F., Marshall, G.W. \& Marshall, S.J., Nano- and micromechanical properties of dentine. Journal of Biomechanics, 44(8), pp. 16261629, 2012.

[37] Kinney, J.H., Balooch, M., Marshall, S.J., Marshall, G.W. \& Weihs, T.P., Hardness and young's modulus of human peritubular and intertubular dentine. Archives of Oral Biology, 41(1), pp. 9-13, 1996.

[38] Miller, M., Bobko, C., Vandamme, M. \& Ulm, F.J., Surface roughness criteria for cement paste nanoindentation. Cement and Concrete Research, 38(4), pp. 467-476, 2008.

[39] Oliver, W.C. \& Pharr, G.M., An improved technique for determining hardness and elastic modulus using load and displacement sensing indentation experiments. Journal of Materials Research, 7(6), pp. 1564-1583, 1992.

[40] VanLandingham, M.R., Review of instrumented indentation. Journal of Research of the National Institute of Standards and Technology, 108(4), p. 249, 2012.

[41] Del Gaudio, C. et al., Natural polymeric microspheres for modulated drug delivery. Materials Science and Engineering: C, 75, pp. 408-417, 2017. 
[42] Hochstetter, G., Jimenez, A. \& Loubet, J.L., Strain-rate effects on hardness of glassy olymers in the nanoscale range. Comparison between quasi-static and continuous stiffness measurements. Journal of Macromolecular Science: Part B, 38(5-6), pp. 681-692, 1999.

[43] Mazeran, P.E., Beyaoui, M., Bigerelle, M. \& Guigon, M., Determination of mechanical properties by nanoindentation in the case of viscous materials. International Journal of Materials Research, 103(6), pp. 715-722, 2012.

[44] Romberg, E. et al., Indentation damage and mechanical properties of human enamel and dentin. Journal of Dental Research, 77(3), pp. 472-480, 1998.

[45] Kinney, J.H., Balooch, M., Marshall, G.W. \& Marshall, S.J., A micromechanics model of the elastic properties of human dentine. Archives of Oral Biology, 44(10), pp. 813822, 1999.

[46] Yoshikawa, T. et al., Long-term durability of dentin bonds made with a self-etching primer, in vivo. Journal of Dental Research, 78(4), pp. 906-911, 1999.

[47] Comba, A. et al., Carbodiimide effect on MMPs and hybrid-layer micro-hardness in radicular dentine. Abstracts of the Academy of Dental Materials Annual Meeting, pp. e29-30, 2018. 